OPEN ACCESS

Edited by:

Qin Li,

Griffith University, Australia

Reviewed by:

Edward Gillan

The University of lowa, United States Zhi Ping (Gordon) Xu,

The University of

Queensland, Australia

*Correspondence:

Vanessa Prevot

vanessa.prevot@uca.fr

Christine Mousty

christine.mousty@uca.fr

Specialty section

This article was submitted to

Electrochemistry,

a section of the journal

Frontiers in Chemistry

Received: 15 May 2020 Accepted: 12 November 2020 Published: 02 December 2020

Citation:

Prevot V, Touati S and Mousty C (2020) Confined Growth of

NiAl-Layered Double Hydroxide Nanoparticles Within Alginate Gel:

Influence on Electrochemical Properties. Front. Chem. 8:561975 doi: 10.3389/fchem.2020.561975

\section{Confined Growth of NiAl-Layered Double Hydroxide Nanoparticles Within Alginate Gel: Influence on Electrochemical Properties}

\author{
Vanessa Prevot*, Souad Touati and Christine Mousty* \\ Université Clermont Auvergne, CNRS, SIGMA Clermont, ICCF, Clermont-Ferrand, France
}

NiAl Layered Double Hydroxide (LDH) alginate bionanocomposites were synthesized by confined coprecipitation within alginate beads. The NiAl based bionanocomposites were prepared either by impregnation by divalent and trivalent metal cations of pre-formed calcium cross-linked alginate beads or by using the metal cations $\left(\mathrm{Ni}^{2+}\right.$, $\mathrm{Al}^{3+}$ ) as crosslinking cationic agents for the biopolymer network. The impregnation step was systematically followed by a soaking in $\mathrm{NaOH}$ solution to induce the LDH coprecipitation. Powder x-ray diffraction (PXRD), infrared spectroscopy (FTIR), energy dispersive X-ray analysis (EDX), thermogravimetry analysis (TGA), electron microscopies (SEM and TEM) confirmed the biotemplated coprecipitation of LDH nanoparticles ranging from 75 to $150 \mathrm{~nm}$ for both strategies. The drying of the LDH@alginate beads by supercritical $\mathrm{CO}_{2}$ drying process led to porous bionanocomposite aerogels when $\mathrm{Ca}^{2+}$ cross-linked alginate beads were used. Such confined preparation of NiAl LDH was extended to bionanocomposite films leading to similar results. The permeability and the electrochemical behavior of these NiAl@alginate bionanocomposites, as thin films coated on indium tin oxide (ITO) electrodes, were investigated by cyclic voltammetry, demonstrating an efficient diffusion of the $\mathrm{K}_{4} \mathrm{Fe}(\mathrm{CN})_{6}$ redox probe through the LDH@alginate based films and the improvement of the electrochemical accessibility of the Ni sites.

Keywords: layered double hydroxides, alginate, confined coprecipitation, bionanocomposites, electrochemical behavior, permeability

\section{INTRODUCTION}

Layered double hydroxides ( $\mathrm{LDH}$ ), also termed anionic clays belong to clay minerals (Forano et al., 2013) with a brucite like layered structure and a general formula $\left[\mathrm{M}_{1-\mathrm{x}}^{2+} \mathrm{M}_{\mathrm{x}}^{3+}(\mathrm{OH})_{2}\right] \mathrm{A}_{\mathrm{x} / \mathrm{n}}^{\mathrm{n}-} \cdot \mathrm{mH}_{2} \mathrm{O}$, where $\mathrm{M}^{2+}$ and $\mathrm{M}^{3+}$ are divalent and trivalent cations, and $\mathrm{A}^{\mathrm{n}-}$ interlayered anions. Although they are rarely observed in the natural state, this family of materials can be easily prepared in the laboratory by different methods such as coprecipitation using $\mathrm{NaOH}$, urea hydrolysis, sol-gel, and epoxide methods (Tokudome et al., 2016; Prevot and Tokudome, 2017; Tichit et al., 2019). Based on fine control of the synthesis conditions, matrices with a tunable chemical composition are prepared by varying the nature of $\mathrm{M}^{2+}$ and $\mathrm{M}^{3+}$, their ratio and the type of anion intercalated which can range from simple inorganic anions, polyoxometalates (Liu et al., 2020) and organic 
or even bioorganic anions bearing carboxylate, sulfonate, or phosphonate groups (Taviot-Guého et al., 2018). Thanks to their unique properties, $\mathrm{LDH}$ are emerging as an important class of layered materials with potential applications as adsorbents in water treatment (Zhang R. et al., 2020), nuclear waste storage materials ( $\mathrm{Gu}$ et al., 2018), electro-photo-catalysts for organic molecule conversion (Fan et al., 2014; Xu and Wei, 2018; Cai et al., 2019; Liu et al., 2020) or pollutant degradation (Zhang G. et al., 2020), energy storage and conversion (Patel et al., 2018; Cai et al., 2019; Xie et al., 2019; Yang et al., 2019), electrode materials for detection (Mousty and Prévot, 2013) and biocompatible inorganic matrices for drug delivery system development (Choi et al., 2018a,b) or biomedical imaging (Jin and Park, 2019).

Recently, the association of LDH particles with biopolymer matrices has gained increasing attention, as the formed bionanocomposites are capable, due to a synergic effect, of providing enhanced multifunctional properties for potential uses in environmental remediation and monitoring, agronomy, biocatalysis, and biomedical applications (Chatterjee et al., 2019). Special attention has been paid to LDH based bionanocomposites involving alginate, which is a large polysaccharide extracted from brown seaweeds consisting of linked $\alpha$-L-guluronic acid and 1, 4 linked $\beta$-D-mannuronic acid residues (Yang et al., 2011). When intercalated within a $\mathrm{ZnAl} \mathrm{LDH}$ structure, alginate was reported to provide enhanced thermal stability to the assembly and to allow the development of both potentiometric sensors and amperometric polyphenol oxidase based biosensors to determine $\mathrm{Ca}^{2+}$ and phenol concentration, respectively (Leroux et al., 2004; Darder et al., 2005; Sanchez-Paniagua Lopez et al., 2010). The alginate LDH assembly can also be obtained in a layer by layer approach leading to a nacre-like film with an ordered layered structure, good flexibility, and high strength (Liang et al., 2017). Interestingly, this latter approach can be applied to $3 \mathrm{D}$ porous support such as polyurethane foam and cotton fabrics to improve their thermal stability, flame retardancy, and smoke suppression (Liu et al., 2015; Pan et al., 2016). Another strategy to develop alginate-based bionanocomposites consisted of dispersing LDH particles in the biopolymer solution and subsequently form beads or films. Pristine $\mathrm{LDH}$ and calcined $\mathrm{LDH}$ embedded into alginate beads and magnetic alginate beads containing iron oxides displayed interesting adsorption properties toward for instance fluoride (Gao et al., 2014), phosphate (Lee and Kim, 2013; Kim, 2014), $\mathrm{Cd}^{2+}, \mathrm{Pb}^{2+}, \mathrm{Cu}^{2+}$ and $\mathrm{CrO}_{4}^{2-}$ (Lee and Kim, 2013; Sun et al., 2018) with enhanced maximum adsorption capacity. Alginate-based drug delivery systems, developed with LDH particles intercalated with molecules such as ciprofloxacin, diclofenac, or ibuprofen (Alcantara et al., 2010; Zhang et al., 2010; Rezvani and Shahbaei, 2015), displayed an improved controlled release behavior which was explained by a limited mobility of the alginate chain due to electrostatic interactions with $\mathrm{LDH}$ particles, a slow-down swelling, and dissolution rates. Biohybrids based on LDH and proteins or enzymes assembly were also embedded in alginate beads to produce systems of interest for oral protein delivery and biocatalysis (Mahkam et al., 2013; Mahdi et al., 2015; Yu et al., 2019).

In parallel, an alginate assisted method was described in the literature to prepare inorganic nanoparticles, taking advantage of the alginate ability to form gels in the presence of divalent and trivalent metal cations due to their interaction with the carboxylic group on the G block of alginate forming "eggbox" like structures (Agulhon et al., 2012, 2014). Inspired by biomineralization, the confined metal cations can easily be converted either in metallic nanoparticles by a reduction step or in metal oxides nanoparticles on simple calcination under an ambient atmosphere. Pd, magnetic $\mathrm{Co}$ and $\mathrm{Ni}, \mathrm{Au}$ metallic nanoparticles (Brayner et al., 2007; Jaouen et al., 2010; Chtchigrovsky et al., 2012), $\mathrm{CeO}_{2}, \mathrm{NiO}, \mathrm{TiO}_{2}$ metal oxides, and Prussian blue type nanoparticles for instance (Primo et al., 2011; Kimling and Caruso, 2012; Tokarev et al., 2012; Wang et al., 2012), were prepared by this alginate-assisted method. The metal cations being well-distributed within the biopolymer network, it limits the crystal growth, suppresses the particle aggregation and preferentially leads to nanoparticle formation.

In this study, the alginate templating method was applied for the synthesis of $\mathrm{NiAl} \mathrm{LDH}$ nanoparticles following two strategies (Figure 1) which involve either pre-formed calcium alginate beads or ion-exchanged nickel and aluminum alginate beads. The structures of the NiAl nanoparticles formed within the biopolymer beads, by soaking in $\mathrm{NaOH}$, have been analyzed after $\mathrm{CO}_{2}$ supercritical drying, using PXRD, FTIR, and EDX to obtain a deep insight into the structure of the bionanocomposite aerogels. The morphology of both the aerogel beads and confined LDH nanoparticles were characterized by Scanning Electron Microscopy (SEM) and Transmission Electron Microscopy (TEM) and described in the following sections. Finally, such confined NiAl LDH coprecipitation was also extended to the preparation of bionanocomposite thin films to investigate the influence on the film permeability and the electrochemical properties of the NiAl nanoparticles formed.

\section{EXPERIMENTAL SECTION}

\section{Materials and Synthesis}

For all preparations, sodium alginate, $\mathrm{NiCl}_{2} \cdot 6 \mathrm{H}_{2} \mathrm{O}$, and $\mathrm{AlCl}_{3}$. $9 \mathrm{H}_{2} \mathrm{O}$ salts were of analytical grade. All other solvents and reagents were of commercial-grade (Aldrich, Acros Organics, Merck, Fluka). For comparison purposes, NiAl- $\mathrm{CO}_{3}$ and hybrid $\mathrm{NiAl}-\mathrm{Alg}$ were prepared by the coprecipitation method as previously reported (Leroux et al., 2004; Faour et al., 2012). Typically, a $1 \mathrm{M}$ solution of $\mathrm{Ni}$ and $\mathrm{Al}$ chloride salts $\left(\mathrm{Ni}^{\mathrm{II}} / \mathrm{Al}^{\mathrm{III}}\right.$ $=2$ ) was added under stirring and nitrogen atmosphere to a reactor containing the anion to be intercalated in a stoichiometric excess of 2 and 4 for carbonate anions and alginate, respectively. The $\mathrm{pH}$ of the solution was systematically maintained at 10.0 by the simultaneous addition of a $1 \mathrm{M} \mathrm{NaOH}$ solution. After addition, the suspension was allowed to stir for $24 \mathrm{~h}$ and then the precipitate was recovered by centrifugation, washed three times with deionized water and allowed to dry at room temperature.

For the microsphere preparation, two different strategies were followed, both using a $2 \%(\mathrm{w} / \mathrm{w})$ aqueous solution of sodium alginate. In strategy 1 (Figure 1), the polymer solution was added dropwise at room temperature to a stirred $\mathrm{CaCl}_{2}$ (Aldrich) solution (10\%) using a syringe with a $0.8 \mathrm{~mm}$ diameter needle. The formed millimeter microspheres were cured in the gelation 


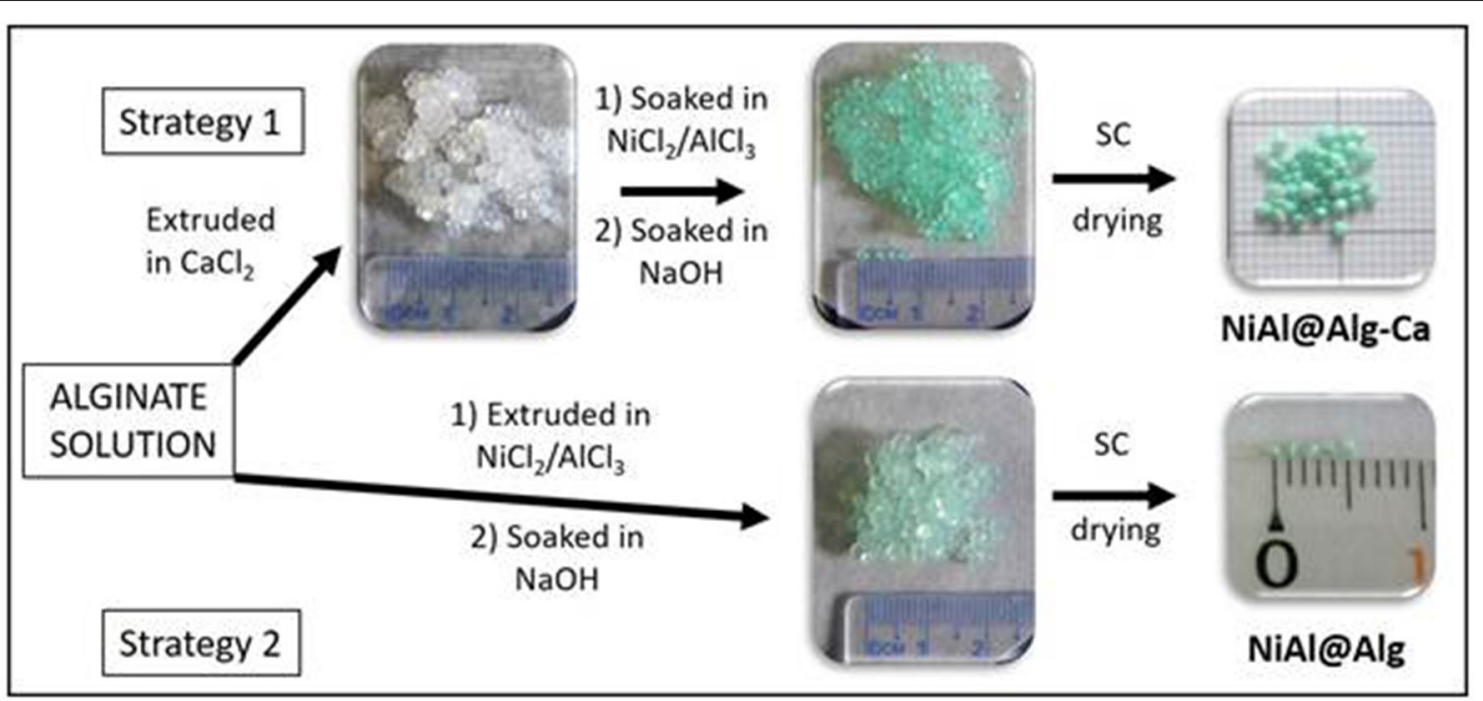

FIGURE 1 | Scheme of preparation of NiAl nanoparticles confined in Alg beads using either Ca-Alg as a template for confined LDH coprecipitation (Strategy 1) or alginate cross-link by $\mathrm{NiCl}_{2}$ and $\mathrm{AlCl}_{3}$ metal salt solution (Strategy 2). For both strategies, the $\mathrm{LDH}$ coprecipitation was induced by soaking in a NaOH (1 M) solution and bionanocomposite beads were dried in $\mathrm{CO}_{2}$ supercritical conditions.

solution for $20 \mathrm{~min}$. Then, the alginate beads were soaked in a $\mathrm{Ni}$ and $\mathrm{Al}$ metal salts solution (ratio $\mathrm{Ni}^{\mathrm{II}} / \mathrm{Al}^{\mathrm{II}}=2$ and $\left[\mathrm{Ni}^{\mathrm{II}}+\mathrm{Al}^{\mathrm{II}}\right]$ $=1 \mathrm{M}$ ) for $24 \mathrm{~h}$. The alginate beads were filtrated and deeply rinsed with deionized water before to be soaked in a $\mathrm{NaOH}$ solution (1 M, 6h). Finally, the beads, noted NiAl@Alg-Ca, were filtrated, washed, and keep in suspension before to be dried. In strategy 2, the biopolymer solution was directly added dropwise at room temperature to a stirred $1 \mathrm{M}$ solution of $\mathrm{Ni}$ and $\mathrm{Al}$ metal salts using a syringe with a $0.8 \mathrm{~mm}$ diameter needle, and the beads were let in the solution for $24 \mathrm{~h}$. Then as described for strategy 1 , the beads, noted NiAl@Alg, were soaked in $\mathrm{NaOH}$ solution (1 M, $6 \mathrm{~h})$, filtrated, washed, and keep in water.

The microspheres prepared by both strategies were dried by $\mathrm{CO}_{2}$ supercritical. Since liquid $\mathrm{CO}_{2}$ is not miscible with water, ethanol was used as an intermediate solvent. The microspheres were dehydrated by immersion in a series of successive ethanolwater baths at an increasing alcohol concentration (10, 20, 50, 80,90 , and $100 \%$ ) for $15 \mathrm{~min}$ each. Finally, the microspheres were dried in an autoclave under supercritical $\mathrm{CO}_{2}$ conditions $\left(105 \mathrm{bar}, 45^{\circ} \mathrm{C}\right)$ in a Top Industry apparatus. After $6 \mathrm{~h}$, the pressure was slowly decreased at constant temperature and then the autoclave was cooled down before to be opened.

\section{Preparation of Modified Electrodes}

$\mathrm{NiAl} \mathrm{LDH}$ thin films were prepared on indium tin oxide electrodes (ITO, $1 \mathrm{~cm}^{2}$ ) as conductive substrates. Before use, the ITO electrodes were cleaned by sonication ( $5 \mathrm{~min}$ ) in acetone, ethanol, and deionized water, successively, and finally dried under $\mathrm{N}_{2}$ flow. Confined preparation of NiAl-LDH was adapted to alginate films coated on these ITO electrodes. Between each step of the preparation, the electrode was rinsed in water. The electrode was first soaked in an alginate aqueous solution (0.2 $\mathrm{w} / \mathrm{w})$ for $3 \mathrm{~h}$ at $60{ }^{\circ} \mathrm{C}$, rinsed in water, and then transferred into a $\mathrm{CaCl}_{2}$ solution $(2.75 \% \mathrm{w} / \mathrm{w})$ for $15 \mathrm{~min}$. This Alg-Ca/ITO modified electrode was immersed in a $\mathrm{Ni}$ and $\mathrm{Al}$ metal salt solution $(1 \mathrm{M}, \mathrm{Ni} / \mathrm{Al}=2)$ for $24 \mathrm{~h}$ and then in a $0.1 \mathrm{M} \mathrm{NaOH}$ solution for $6 \mathrm{~h}$. This modified electrode is referred as NiAl@Alg$\mathrm{Ca} / \mathrm{ITO}$. The same procedure was repeated to prepare the NiAl@Alg/ITO modified electrode. In this case, the soaking step in the $\mathrm{CaCl}_{2}$ solution was skipped. Two other reference electrodes were prepared with $100 \mu \mathrm{L}$ of overnight stirred 2 $\mathrm{mg} / \mathrm{mL} \mathrm{NiAl}-\mathrm{CO}_{3}$ or NiAl-Alg suspensions deposited onto ITO electrodes and dried in air for $4 \mathrm{~h}$.

\section{Instrumentation and Electrochemical Characterization}

NiAl@Alginate bionanocomposites were characterized using different analytical techniques. X-ray diffraction patterns were recorded with a Philips X'Pert automated X-ray diffractometer using CuK $\alpha$ radiation $(\lambda=0.154051 \mathrm{~nm})$, over the $2-70^{\circ}(2 \theta)$. FTIR spectra were recorded with a Nicolet 5,700 spectrometer from Thermo Electron Corporation using the $\mathrm{KBr}$ pellet technique. Thermogravimetric analyses (TGA) were performed using a Setaram TGA92 thermogravimetric analyzer in the temperature range of $25-1,050^{\circ} \mathrm{C}$, with a heating rate of $5^{\circ} \mathrm{C} \mathrm{min}^{-1}$, under air atmosphere. SEM characteristics of the samples were imaged by a Zeiss supra 55 FEG-VP operating at $3 \mathrm{keV}$ combined with an energy dispersive X-ray (EDX) analyzer. Specimens were mounted on conductive carbon adhesive tabs and imaged after $\mathrm{Au}$ sputter coating to make them conductive. $\mathrm{N}_{2}$ adsorption/desorption isotherms were collected in a Micromeritics ASAP2020 analyzer at $-196^{\circ} \mathrm{C}$. Before measurements, the samples were degassed at $80^{\circ} \mathrm{C}$ for $12 \mathrm{~h}$. The surface area measurements were performed using the Brunauer-Emmet-Teller (BET) method. The film thicknesses were measured with an Alpha-step IQ surface profiler 
(KLA 134Tencor). Electrochemical measurements were made with a BioLogic Science Instruments SP-150 using a threeelectrode cell, including a saturated calomel electrode (SCE) as a reference electrode, a platinum auxiliary electrode and the $\mathrm{NiAl}$ LDH/ITO modified electrodes as working electrodes. Cyclic voltammograms were recorded in $1 \mathrm{mM} \mathrm{K}_{4} \mathrm{Fe}(\mathrm{CN})_{6}$ dissolved in Tris buffer $(0.1 \mathrm{M} \mathrm{pH} \mathrm{7)}$ and $0.1 \mathrm{M} \mathrm{NaOH}$ solution, respectively.

\section{RESULTS AND DISCUSSION}

\section{Confined NiAI LDH Coprecipitation}

$\mathrm{NiAl} \mathrm{LDH}$ nanoparticles were prepared via template-assisted coprecipitation within an alginate (Alg) matrix thanks to soaking in mixed metal salt solution and concentrated sodium hydroxide solution (Figure 1). Such confined LDH coprecipitation by successive impregnations was previously described by our group to successfully lead to three-dimensional macroporous $\mathrm{LDH}$ using polystyrene colloidal crystal as a sacrificial hard template (Géraud et al., 2008). In a first strategy, Ca-alginate beads, obtained by alginate ion cross-link in a calcium chloride solution, were submitted to a solvent exchange process to introduce $\mathrm{Ni}^{2+}$ and $\mathrm{Al}^{3+}$ in the hydrogel network. The infiltration of the metal cation solution was traduced by the color change of the beads from white to light green (Figure 1), demonstrating the efficient diffusion of the solution within the biopolymer network. Since the $\mathrm{pH}$ of the infiltrated metal salt solution is $\sim 3.0, \mathrm{Al}^{3+}$ and $\mathrm{Ni}^{2+}$ are the main infiltrated species, although the presence of $\mathrm{Al}(\mathrm{OH})^{2+}$ and $\mathrm{Al}(\mathrm{OH})_{2}^{+}$cannot be excluded. No modification of the bead size and aspect was observed during infiltration and subsequent soaking in sodium hydroxide solution. To be able to characterize the Alg-Ca bionanocomposites by solidstate techniques, the beads were dried. While drying in a stove at $40^{\circ} \mathrm{C}$ let to a net diminution of the bead size due to an important shrinkage of the alginate network, the drying using supercritical $\mathrm{CO}_{2}\left(\mathrm{CO}_{2} \mathrm{SC}\right)$ conditions allowed to preserve the sphericity of the beads and limit the size decrease. TGA analyses (Supplementary Figure 1) of the sodium alginate used as a precursor and the Alg-Ca beads dried by the two different ways revealed that systematically the thermal decomposition occurred in four steps around $120^{\circ} \mathrm{C}, 200-240^{\circ} \mathrm{C}, 510-600^{\circ} \mathrm{C}$ and $675-$ $1,010^{\circ} \mathrm{C}$, leading to a total mass loss comprised between 93.5 and 88.1\% (Table 1 and Supplementary Table 1). The decomposition steps can be attributed according to the literature (dos Santos Araújo et al., 2019) to the dehydration of the matrix, the biopolymer decomposition, the corresponding carbonate salt formation $\left(\mathrm{Na}_{2} \mathrm{CO}_{3}\right.$ and $\left.\mathrm{CaCO}_{3}\right)$ and at higher temperature their decomposition. Note that the thermal profiles below $200^{\circ} \mathrm{C}$, corresponding to the dehydration step, showed a net difference in the water amount into the beads with 14.7 and $44.3 \%$ of mass loss for the Alg-Ca beads dried in the stove and $\mathrm{CO}_{2} \mathrm{SC}$ conditions, respectively. This can be attributed to the ability of $\mathrm{CO}_{2} \mathrm{SC}$ conditions to better maintain the hydration rate into the aerogel network. Since the dehydration step occurred at a lower temperature, the $\mathrm{CO}_{2} \mathrm{SC}$ conditions seem also to favor the diffusion and the mass transfer in the biopolymer network.

Then, in the following the biopolymer beads were systematically dried using this latter technique leading to
TABLE 1 | Main structural characteristics of the LDH and alginate-based bionanocomposites.

\begin{tabular}{|c|c|c|c|c|c|c|}
\hline Sample & $\begin{array}{l}d_{\text {inter }} \\
(n m)\end{array}$ & $\begin{array}{c}a \\
(n m)\end{array}$ & $\begin{array}{c}D_{006} / D_{110}^{*} \\
(n m)\end{array}$ & $\begin{array}{l}\mathrm{Ni} / \mathrm{Al} \\
\text { ratio }\end{array}$ & $\begin{array}{c}\text { BET } \\
\left(\mathrm{m}^{2} / \mathrm{g}\right)\end{array}$ & $\begin{array}{c}\text { Mass loss } \\
(\%)\end{array}$ \\
\hline Alg-Ca & - & - & - & - & 168 & 91 \\
\hline NiAl@Alg-Ca & 0.75 & 0.304 & $1.98 / 3.96$ & 3.5 & 423 & 49 \\
\hline NiAl@Alg & 0.74 & 0.301 & $2.08 / 3.50$ & 3.2 & 33 & 51 \\
\hline NiAl-Alg & 1.27 & 0.299 & - & - & - & 55 \\
\hline $\mathrm{NiAl}-\mathrm{CO}_{3}$ & 0.76 & 0.299 & 2.68/3.11 & 2.1 & 72 & 39 \\
\hline
\end{tabular}

*determined using Scherrer equation.

beads with the size of the order of a millimeter. SEM images of a NiAl@Alg-Ca aerogel (Figures 2A-D) showed their morphology was similar to the one observed for Alg-Ca precursor beads (Supplementary Figure 2) with a well-defined smooth surface, while images at higher magnification revealed a nested network based on small filaments, characteristic of biopolymer hydrogel. The presence of NiAl particles within the network was very difficult to be distinguished. In a second strategy, the biopolymer network was directly cross-linked by the addition of the sodium alginate solution in the $\mathrm{Ni}^{2+}$ and $\mathrm{Al}^{3+}$ chloride solution.

It is known that not only $\mathrm{Ca}^{2+}$ displays the ability to interact with the $G$ blocks of the alginate to form an eggbox structure and ionotropic gelation, other divalent and trivalent cations, such as $\mathrm{Cu}^{2+}, \mathrm{Ba}^{2+}, \mathrm{Co}^{2+}, \mathrm{Ni}^{2+}$, and $\mathrm{Zn}^{2+}$, can also be used (Agulhon et al., 2012, 2014), even if their affinity toward alginate can differ. Following this approach and subsequent soaking in $\mathrm{NaOH}, \mathrm{NiAl} @ A l g$ beads were formed with a size slightly higher compared to the NiAl@Alg-Ca, which can be attributed to a lower affinity of the cations $\mathrm{Ni}^{2+}$ and $\mathrm{Al}^{3+}$ for alginate compared to $\mathrm{Ca}^{2+}$, leading to a less reticulated and dense gel. Such properties of the beads induced after the $\mathrm{CO}_{2} \mathrm{SC}$ drying, a more pronounced shrinkage of the NiAl@Alg aerogel beads displaying an average size below one millimeter. As previously described for NiAl@Alg-Ca, the SEM images showed the morphology of the beads with a smooth surface and in the inner a network characteristic of a biopolymer (Figures 2E-H). To get further insight on the $\mathrm{NiAl} \mathrm{LDH}$ coprecipitation within the two kinds of alginate beads (Strategy 1 and 2), PXRD and FTIR analyses were carried out (Figure 3).

Compared to the amorphous structure of the Alg-Ca beads (Supplementary Figure 3A), the PXRD patterns of the NiAl@Alg-Ca and NiAl@Alg beads (Figure 3A) displayed the characteristic diffraction lines of hexagonal LDH structure, which crystallizes in an R-3m space group, with especially the 003 and 006 reflections, traducing the stacking in the layered structure and the 110 reflections related to the octahedral sheets and the interatomic distance. Such diagrams for the beads revealed as expected, the $\mathrm{NiAl} \mathrm{LDH}$ formation within the biopolymer network for both strategies. In all the case, the width of the diffraction lines appeared wide reflecting small coherent domains for both $\mathrm{D}_{006}$ and $\mathrm{D}_{110}$ (Table 1) and a low level of crystallinity comparable to the coprecipitated $\mathrm{NiAl}-\mathrm{CO}_{3}$ phase. 

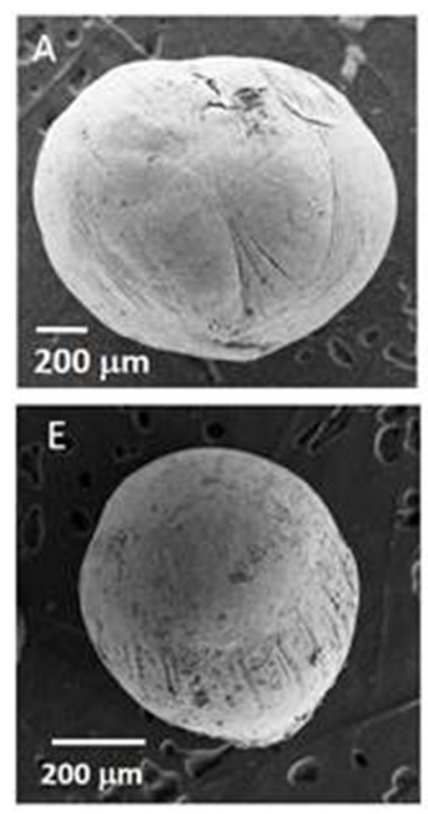
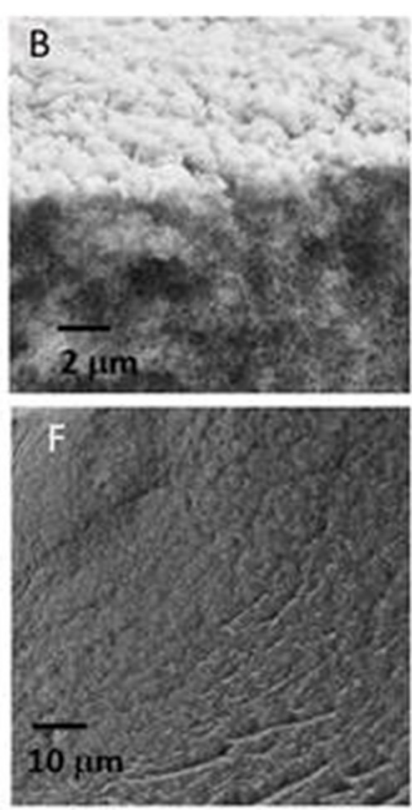
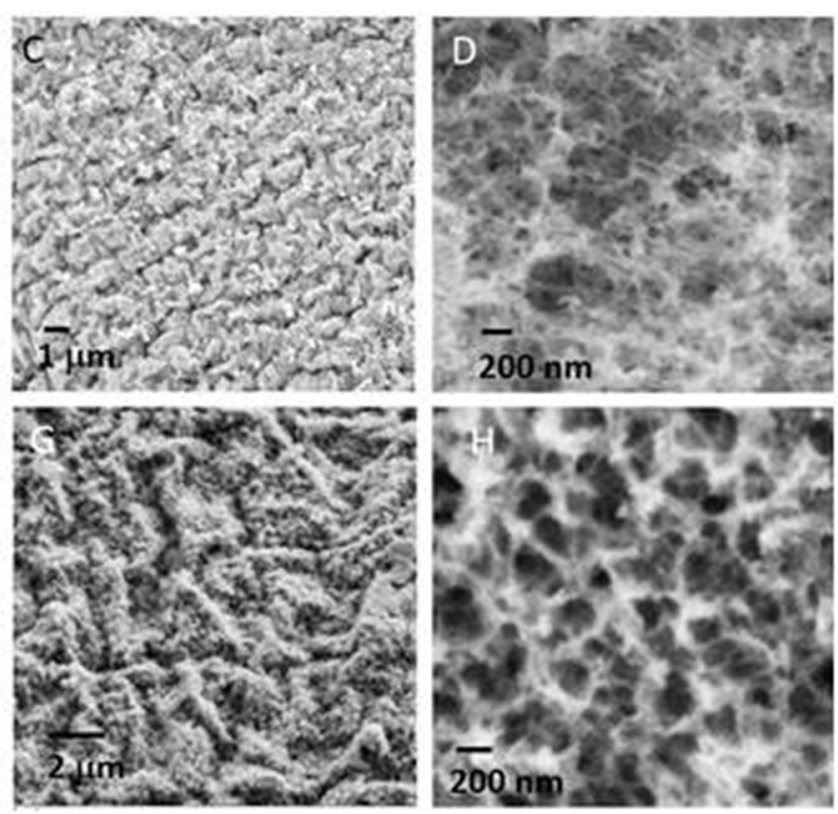

FIGURE 2 | SEM images of (A-D) NiAl@Alg-Ca beads and (E-H) NiAl@Alg beads dried upon $\mathrm{CO}_{2}$ supercritical conditions.

A

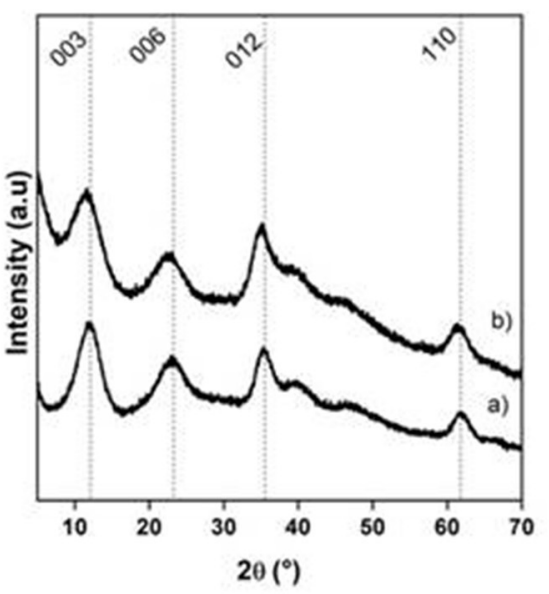

B

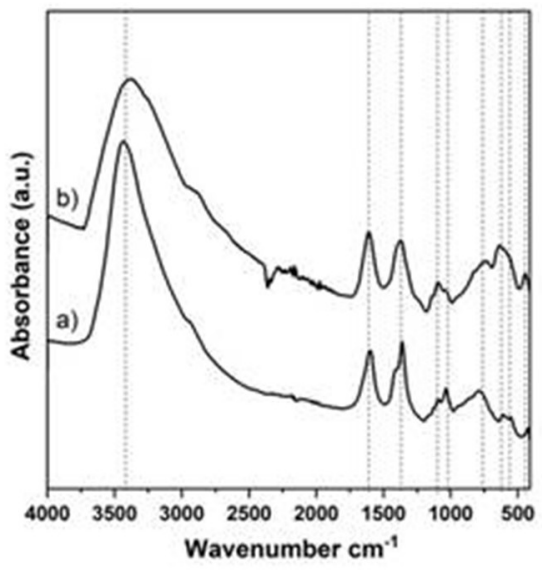

FIGURE 3 | (A) PXRD patterns and (B) FTIR spectra of (a) NiAl@Alg-Ca beads and (b) NiAl@Alg beads dried upon CO 2 supercritical conditions.

The interlayer distance observed (Table 1) is in good agreement with the presence of carbonate anions in between the LDH layer since carbonate anions displayed a high affinity toward $\mathrm{LDH}$ matrices and no precaution was taken during the coprecipitation.

Noticeably, the conditions used in this work were not in favor of alginate intercalation described when LDH was coprecipitated in a sodium alginate solution (Leroux et al., 2004), which lead to an interlayer domain expansion and an interlamellar distance of $1.27 \mathrm{~nm}$ (Supplementary Figure 4). The anionic carboxylic groups being already involved in the egg box alginate structure; we can hypothesize that they were no more available to compensate the positive charge of the
NiAl LDH layer during the coprecipitation. Further evidence of the presence of carbonate anions was provided by FTIR spectroscopy (Figure 3B) due to the presence of a band at 1,371 $\mathrm{cm}^{-1}$ corresponding to the stretching band of the carbonate anions. In the same area, the $\nu_{\mathrm{as}}$ and $\nu_{\mathrm{s}}$ of the carboxylate group of the alginate can also be observed at 1,589 and 1,417 $\mathrm{cm}^{-1}$. Note that in the case of NiAl@Alg beads, even if it was difficult to distinguish between the two bands $v_{\mathrm{s}} \mathrm{COO}-$ and the $v_{\mathrm{CO} 3}$ which appeared as one single large band, the change in $\nu_{\mathrm{as}} / \nu_{\mathrm{s}}$ intensity ratio compared to sodium alginate reference spectrum (Supplementary Figure 5B) is in favor of the carbonate presence. It is noteworthy that in addition to the alginate and carbonate bands, the $\mathrm{LDH}$ lattice vibrations 

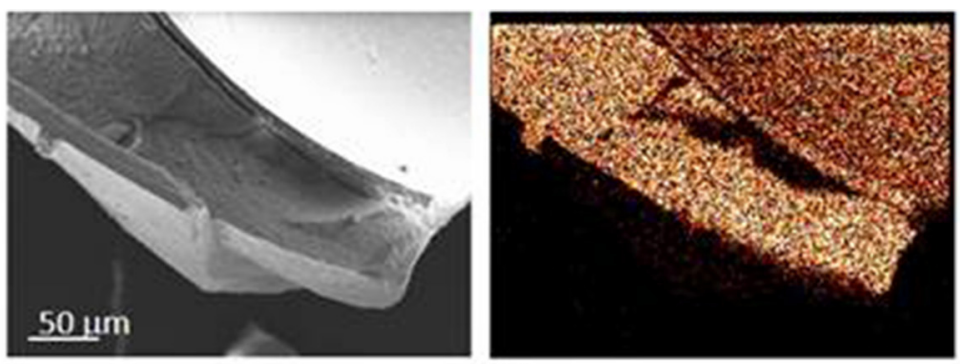

A Ka1

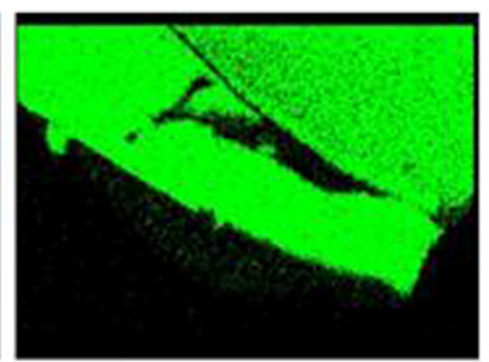

NiLa1_2

FIGURE 4 | Energy dispersive X-ray (EDX) mapping analysis of NiAl@Alg-Ca.

$\left(v_{\mathrm{M}-\mathrm{O}}\right.$ and $\left.\nu_{\mathrm{O}-\mathrm{M}-\mathrm{O}}\right)$ were observed on the spectra below $900 \mathrm{~cm}^{-1}$.

The chemical composition and particularly the $\mathrm{Ni} / \mathrm{Al}$ ratios of the different beads were obtained by EDX (Supplementary Figure 6). The slight difference for the $\mathrm{Ni}^{2+} / \mathrm{Al}^{3+}$ ratio was observed compared to the ratio of 2 used in the precursor solution. Systematically higher ratios (Table 1) were measured which may be due to either a preferential infiltration and affinity of $\mathrm{Ni}^{2+}$ within the polymer network compared to $\mathrm{Al}^{3+}$ or the high $\mathrm{pH}$ used for the $\mathrm{LDH}$ formation during the soaking process in concentrated $1 \mathrm{M} \mathrm{NaOH}$, which could favor the formation of $\mathrm{Al}(\mathrm{OH})_{4}^{-}$species in solution rather than its precipitation within the $\mathrm{LDH}$ layers. Interestingly, EDX mapping showed a homogeneous repartition of the $\mathrm{Ni}^{2+}$ and $\mathrm{Al}^{3+}$ elements within the beads (Figure 4), traducing that the alginate template-assisted coprecipitation induced a good repartition of the $\mathrm{LDH}$ particles within the biopolymer network without segregation.

The observation by TEM of ultra-thin section obtained from the wet NiAl@Alg-Ca beads included in a resin (Figures 5A,B) showed the presence of a dense biopolymer network, in good agreement with the SEM images. At higher magnification, dispersed well-defined hexagonal LDH platelets were observed which seemed to be embedded within the biopolymer. These observations strongly contrast with the images obtained from $\mathrm{NiAl@Alg} \mathrm{beads} \mathrm{(Figures} \mathrm{5} \mathrm{C,D)} \mathrm{which} \mathrm{indicated} \mathrm{a} \mathrm{much-}$ opened network for alginate which may be correlated to the lower affinity of alginate for $\mathrm{Ni}^{2+} / \mathrm{Al}^{3+}$ compared to $\mathrm{Ca}^{2+}$ as previously discussed. Moreover, a completely different LDH particle shape was observed for the NiAl@Alg beads. The NiAl- nanoparticles strongly interacted with the biopolymer chains and were mainly observed on the edge. Such morphology is to be related to the use of $\mathrm{Ni}^{2+}$ and $\mathrm{Al}^{3+}$ as cross-linking ions in the second strategy which imposes a strong interaction between the biopolymer molecular chain and the metal cations to be involved in the LDH layers.

The choice of the strategy followed also impacted strongly the textural properties of the dried bionanocomposite beads, as highlighted by the $\mathrm{N}_{2}$ adsorption-desorption isotherms (Figure 6A). The two isotherms displayed the same characteristic shape (Type IV with hysteresis loop is H3) of a mesoporous material, also observed for Alg-Ca beads

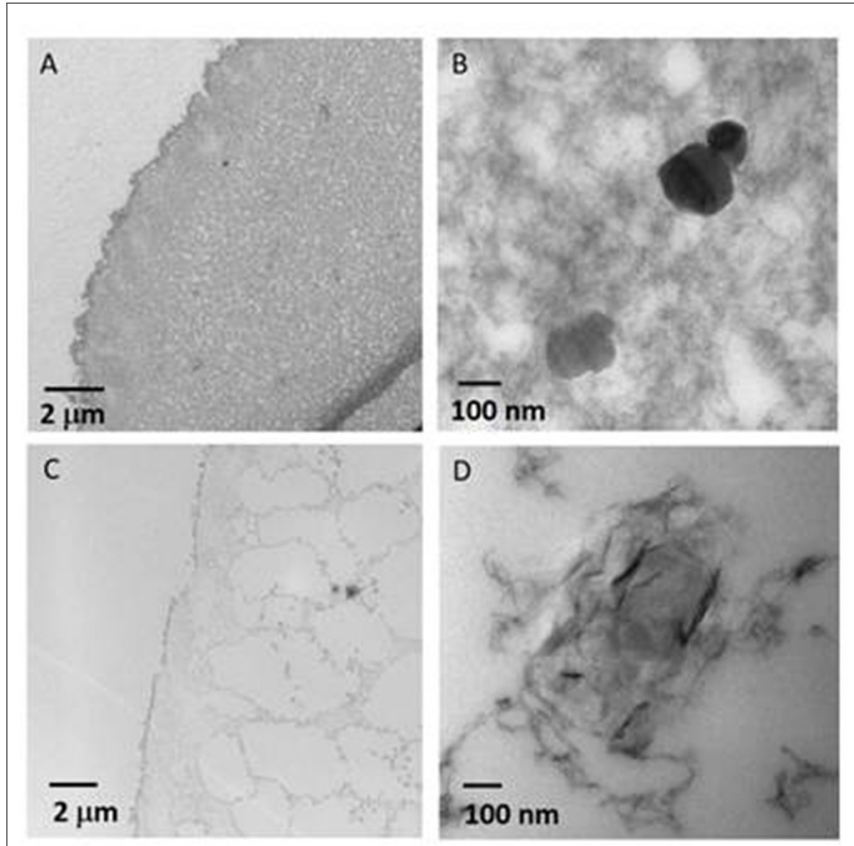

FIGURE 5 | TEM images of ultrathin sections obtained by ultramicrotomy from wet $(\mathbf{A}, \mathbf{B}) \mathrm{NiAl} @$ Alg-Ca beads, and (C,D) NiAl@Alg beads.

(Supplementary Figure 3). However, successive infiltrations of pre-formed Alg-Ca beads (Strategy 1) led to more porous NiAl@Alg-Ca beads with a high BET surface area of 423 $\mathrm{m}^{2} \mathrm{~g}^{-1}$ with a pore volume of $0.81 \mathrm{~cm}^{3} / \mathrm{g}$. The pore size distribution showed well-defined mesopores with a size centered at $3.5 \mathrm{~nm}$ mainly distributing from 2.0 to $5.0 \mathrm{~nm}$ (Supplementary Figure 7). We assumed that the shrinkage observed during drying for strategy 2 strongly reduced the beads' porosity (Table 1).

In parallel, the presence of the $\mathrm{LDH}$ nanoparticles within the biopolymer networks had an important influence on the thermal behavior of the materials (Figure 6B and Table 1). On one hand, the decomposition process of the NiAl@Alg aerogel beads occurred at a lower temperature compared to $\mathrm{NiAl@Alg-Ca} \mathrm{aerogel,} \mathrm{which} \mathrm{may} \mathrm{be} \mathrm{explained} \mathrm{by} \mathrm{biopolymer}$ 

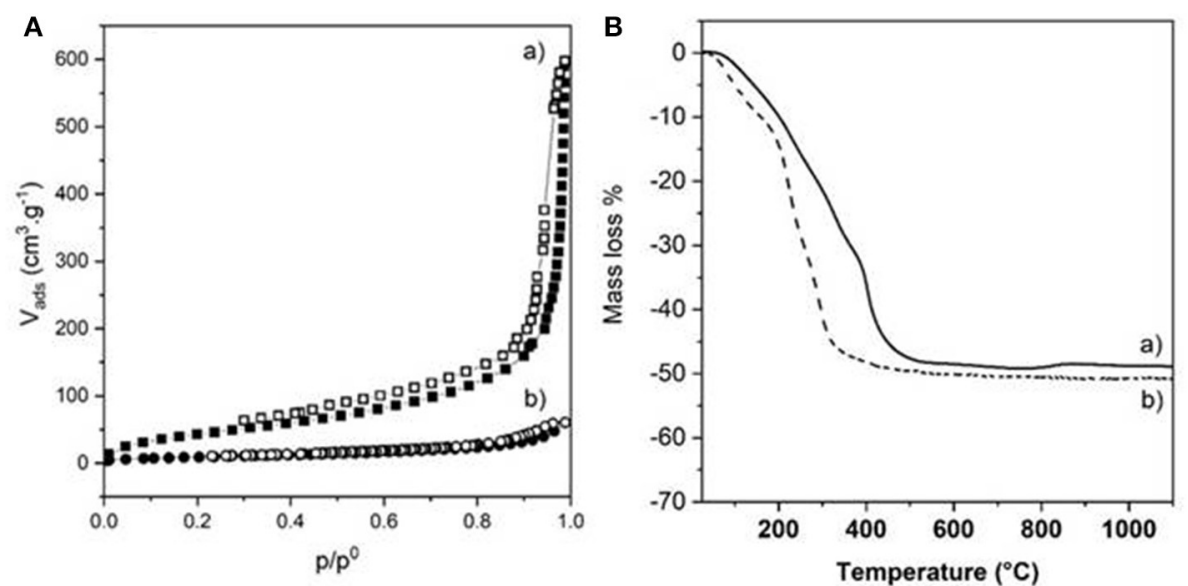

FIGURE 6 | (A) N2 adsorption-desorption isotherms and (B) TGA curves of (a) NiAl@Alg-Ca beads and (b) NiAl@Alg beads dried upon CO 2 supercritical conditions.

combustion favored by the proximity with the NiAl LDH nanoparticles and the derived $\mathrm{NiAl} \mathrm{LDH}$ mixed oxides formed at the intermediate temperatures. However, systematically the presence of $\mathrm{NiAl} \mathrm{LDH} \mathrm{nanoparticles} \mathrm{delayed} \mathrm{the} \mathrm{decomposition}$ in the low-temperature range (Supplementary Figure 1). On the other hand, for both types of bionanocomposite beads, the TGA curves showed a complete decomposition at $500^{\circ} \mathrm{C}$ with a fairly similar total mass loss close to $50 \%$ and very different thermal profiles from that observed for pure Alg-Ca beads (Supplementary Table 1 and Supplementary Figure 1). The decomposition steps of the biopolymer and the inorganic matrix (dehydration/dehydroxylation/decarbonation) are overlapped preventing a clear description of the decomposition. The net decrease of the total mass loss compared to Alg-Ca beads (Table 1) allowed to estimate the amount of NiAl within the bionanocomposites at $\sim 80 \%$ in mass. These results highlighted that the alginate hydrogels were efficient to confine the coprecipitation of a large amount of $\mathrm{NiAl}$ nanoparticles.

\section{Toward 2-D NiAl@Alginate Modified Electrodes}

The relevance of Ni-based LDH in electrochemical applications, such as electrochemical analysis (Tonelli et al., 2013), energy storage (Patel et al., 2018), electrocatalytic oxygen evolution (OER) (Anantharaj et al., 2017) or electrochromism (Mondal and Villemure, 2012; Martin et al., 2016), has been widely described in the literature. NiAl LDH modified electrodes were prepared by different procedures, for instance by the solvent casting of aqueous suspensions of $\mathrm{LDH}$ prepared by the coprecipitation (Vialat et al., 2013; Taviot-Gueho et al., 2016) or the polyol method (Faour et al., 2012) and by the direct electrodeposition on the electrode surface (Scavetta et al., 2007; Tonelli et al., 2013; Mousty and Walcarius, 2015). All these cited works describe the importance of the particle size, the aggregation state of $\mathrm{LDH}$ particles, and the presence of structural defects on the electrochemical activity of nickel sites. The confined coprecipitation of $\mathrm{NiAl} \mathrm{LDH}$ described previously
TABLE 2 | Characterization of the NiAl LDH/ITO modified electrodes.

\begin{tabular}{lccc}
\hline LDH/ITO & $\begin{array}{c}\text { Thickness } \\
(\boldsymbol{\mu} \mathbf{m})\end{array}$ & $\begin{array}{c}\mathbf{D}_{\text {app }}^{\mathbf{a}} \\
\left(\mathbf{c m}^{\mathbf{2}} \mathbf{~ s}^{-\mathbf{1}}\right)\end{array}$ & $\begin{array}{c}\mathbf{I p}_{\mathbf{a}}^{\mathbf{b}} \\
\left(\mathbf{m A ~} \mathbf{~ m}^{-\mathbf{2}} \mathbf{)}\right.\end{array}$ \\
\hline $\mathrm{NiAl@Alg-Ca}$ & 0.41 & $7 \times 10^{-7}$ & 5.3 \\
$\mathrm{NiAl@Alg}$ & 0.40 & $5 \times 10^{-7}$ & 1.6 \\
$\mathrm{NiAl}-\mathrm{Alg}$ & 0.91 & $2 \times 10^{-7}$ & 0.08 \\
$\mathrm{NiAl}-\mathrm{CO}_{3}$ & 2.00 & $9 \times 10^{-8}$ & 0.04 \\
\hline
\end{tabular}

${ }^{a}$ Apparent diffusion coefficient calculated for $1 \mathrm{mM} \mathrm{K} \mathrm{Fe}_{4}(\mathrm{CN})_{6},{ }^{b}$ Anodic peak current recorded in $0.1 \mathrm{M} \mathrm{NaOH}$ at $v=50 \mathrm{mVs}^{-1}$.

was therefore extended to alginate films coated on ITO electrodes to characterize the electrochemical accessibility of $\mathrm{Ni}$ sites in these bionanocomposite materials.

Thin films of alginate, reticulated or not with $\mathrm{Ca}^{2+}$, were prepared on ITO as described in the literature (Yang et al., 2010) (see the experimental part). An ITO electrode was chosen to improve the adhesion of the biopolymer in comparison to a Pt surface. These homogeneous films, as shown in SEM images (Supplementary Figure 8), have a thickness of 1.1 and $0.62 \mu \mathrm{m}$, respectively, before and after the reticulation step. The NiAl@Alg-Ca/ITO and NiAl@Alg/ITO electrodes were prepared by impregnation of these as-prepared alginate films by a $\mathrm{Ni}$ and Al metal salt solution, as previously described for the alginate beads. The formation of the confined $\mathrm{NiAl} \mathrm{LDH}$ phase was confirmed by PXRD leading to a similar diagram to the one described previously (Supplementary Figure 8 and Figure 3). The formation of the $\mathrm{NiAl} \mathrm{LDH}$ phase within the alginate films caused a decrease of the film thickness (Table 2) and some cracks appear in the films (Supplementary Figure 8). For comparison, two other electrodes, namely NiAl-Alg/ITO and $\mathrm{NiAl}-\mathrm{CO}_{3} / \mathrm{ITO}$, were prepared by the deposition of $200 \mu \mathrm{g} / \mathrm{cm}^{2}$ of LDH suspensions. The thicknesses of these films were slightly higher (Table 2).

The permeability of the NiAl@Alg and NiAl@Alg-Ca thin films was investigated with potassium ferrocyanide as an 
electroactive probe, showing a reversible signal in cyclic voltammetry (CV) (Supplementary Figure 9). Based on the variation of the anodic current $\left(\mathrm{ip}_{\mathrm{a}} / \mathrm{A}\right)$ as a function of square root of the scan rate $\left(v^{1 / 2}\right)$, apparent diffusion coefficients $\left(D_{\text {app }}\right)$ were calculated from Randles-Sevcik equation: ip $=2.69 \times 10^{5}$ $\mathrm{n}^{3 / 2}$ A.C v $\mathrm{v}^{1 / 2} \mathrm{D}^{1 / 2}$, where $n=1 \mathrm{e}^{-}$transfer, $\mathrm{C}=1 \times 10^{-6}$ mol cm $\mathrm{cm}^{3}, \mathrm{~A}=$ electrode surface $\left(1 \mathrm{~cm}^{2}\right)$. The calculated values of $\mathrm{D}_{\text {app }}$ are compared to those obtained with the NiAl-Alg and $\mathrm{NiAl}_{-} \mathrm{CO}_{3}$ modified electrodes (Supplementary Figure 9 and Table 2). The diffusion of the electroactive probe through the NiAl@Alg composite films was not perturbed, with a linear variation of the I $\mathrm{I}_{\mathrm{a}} \mathrm{fct} \sqrt{ } v$ over the whole investigated scan rate range (Figure 8 and Supplementary Figure 9). However, with

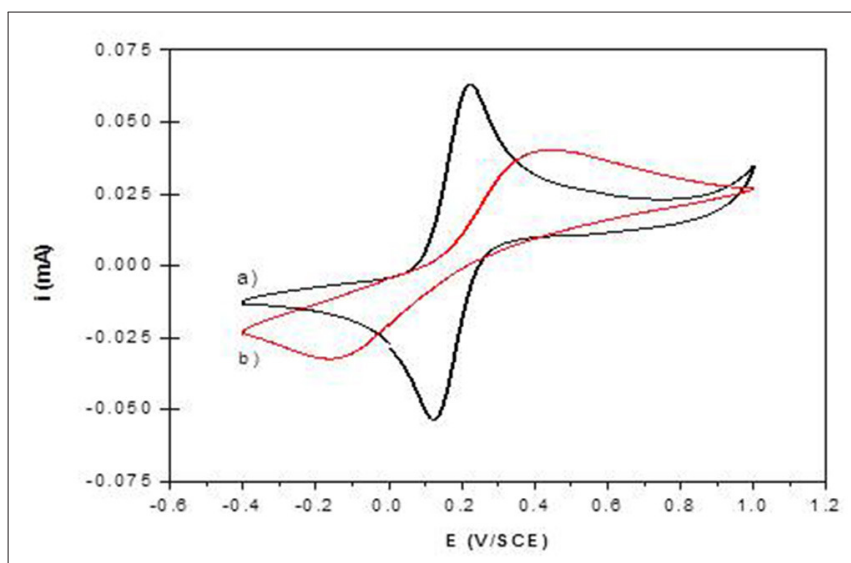

FIGURE 7 | Cyclic voltammograms of $1 \mathrm{mM} \mathrm{K}_{4} \mathrm{Fe}(\mathrm{CN})_{6}$ in $0.1 \mathrm{M}$ Tris buffer $(\mathrm{pH}$ 7) recorded at (a) NiAl@Alg-Ca/ITO and (b) NiAl-CO $C_{3} / \mathrm{ITO}(\mathrm{v}=50 \mathrm{mVs}-1)$. the NiAl- $\mathrm{CO}_{3} / \mathrm{ITO}$, the electron transfer became slower with an increase of $\triangle \mathrm{Ep}$ and smaller peak intensities. In this case, the origin of the straight line differed from zero and the calculated $\mathrm{D}_{\text {app }}$ value was very small, suggesting the possible accumulation of the redox probe $\mathrm{Fe}(\mathrm{CN})_{6}^{4-}$ and the hindrance of its diffusion within the film. It should be noted that the film was thicker in this latter case. With the NiAl-Alg, the situation seems to be intermediate with a possible accumulation of the probe in the film but with higher mobility. We assumed that the confined coprecipitation of the $\mathrm{NiAl} \mathrm{LDH}$ nanoparticles within the porous network of the biopolymer favor the diffusion and the film permeability as illustrated in Figure 8.

The electrochemical behavior of $\mathrm{NiAl} \mathrm{LDH}$ in an alkaline medium is characterized in cyclic voltammetry by a quasireversible one-electron transfer $\mathrm{Ni}(\mathrm{II}) / \mathrm{Ni}(\mathrm{III})$, defined by an anodic peak and its corresponding cathodic peak situated between 0.40 and $0.80 \mathrm{~V} / \mathrm{SCE}$. In a previous study, we have shown that the peak position and intensity depend on the $\mathrm{pH}$ of the electrolyte solution and the nature of the alkali cations; the best signal being obtained in $\mathrm{NaOH}$ (Vialat et al., 2013; TaviotGueho et al., 2016). NiAl- $\mathrm{CO}_{3} / \mathrm{ITO}$ displayed a typical CV signal corresponding to the oxidation of the $\mathrm{Ni}$ sites in the $\mathrm{LDH}$ layer (Figure 9A). It should be noted that the electron transfer seems to be slightly slowdown at the ITO interface, with a higher $\Delta \mathrm{Ep}$ compared to that generally observed at a Pt electrode (Vialat et al., 2015). With NiAl-Alg/ITO, the electrochemical signal seems to be slightly enhanced, probably due to the better permeability of the film which allows better diffusion of the electrolyte ions. Interestingly, the NiAl@alginate bionanocomposites displayed more intense signals (Figure 9B), with a particularly high anodic current for the NiAl@Alg-Ca/ITO (Table 2). Indeed, this current density, recorded at $50 \mathrm{mVs}^{-1}$ in $0.1 \mathrm{M} \mathrm{NaOH}\left(5.3 \mathrm{~mA} \mathrm{~cm}{ }^{-2}\right)$,

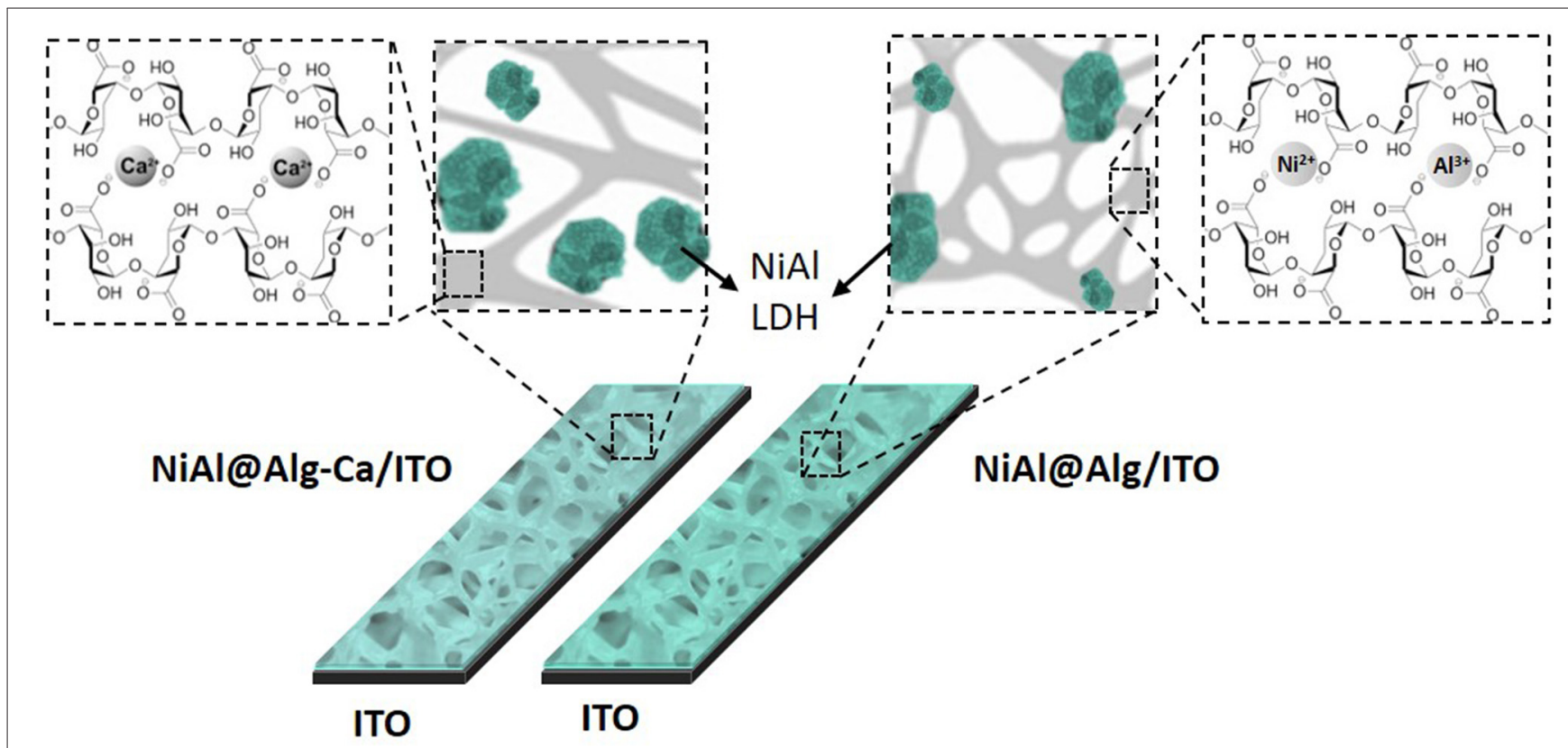

FIGURE 8 | Schematic representation of the NiAl@Alg-Ca/ITO and NiAl-Alg/ITO. 

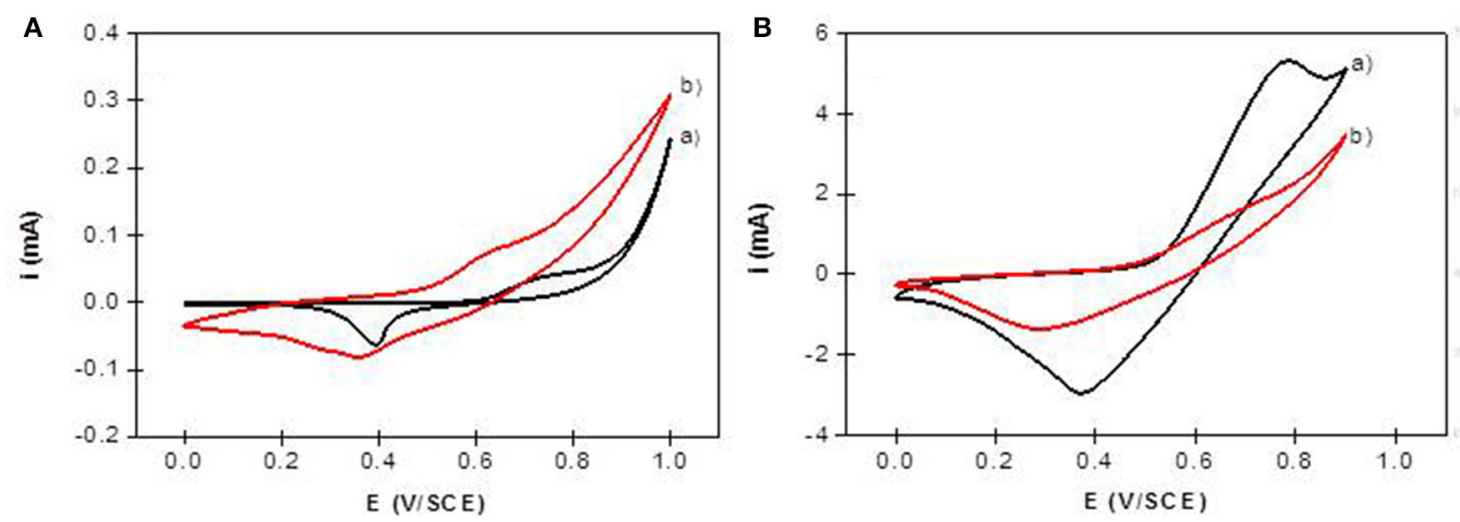

FIGURE 9 | Cyclic voltammograms recorded in $0.1 \mathrm{M} \mathrm{NaOH}\left(\mathrm{v}=50 \mathrm{mVs}^{-1}\right)$ using (A) NiAl-CO $3 /$ ITO (curve a) and NiAl-Alg/ITO (curve b) modified electrodes prepared by solvent casting; (B) NiAl@alginate composite electrodes prepared by impregnation (a) NiAl@Alg-Ca/ITO and (b) NiAl@Alg/ITO.

is two times larger than the value $\left(2.5 \mathrm{~mA} \mathrm{~cm}^{-2}\right)$ we previously found with a Pt electrode modified with a NiAl- $\mathrm{CO}_{3}$ compound, prepared by a glycine-assisted hydrothermal method, where the presence of $2 \mathrm{H} 1$ stacking motifs in the $3 \mathrm{R} 1 \mathrm{LDH}$ lattice results in an enhanced electrochemical signal (Faour et al., 2012). This shows that Ni sites in LDH nanoparticles obtained by templateassisted coprecipitation in the alginate matrix are more accessible for an electron transfer.

\section{CONCLUSION}

In this paper, we reported that the bioinspired alginate-assisted coprecipitation of $\mathrm{NiAl} \mathrm{LDH}$ nanoparticles was possible using two different strategies. The first one based on successive impregnations of alginate beads formed by extrusion in a $\mathrm{CaCl}_{2}$ solution allowed the formation of well-defined carbonate intercalated $\mathrm{NiAl}$ nanoparticles distributed within the biopolymer network. The beads dried in $\mathrm{CO}_{2}$ supercritical conditions displayed high surface area and were stabilized in the low-temperature range. The second strategy involved ion crosslinking of the alginate directly by the metal cations expected to coprecipitate and form the LDH layers. In this case, the hydrogel was less reticulated and the formed $\mathrm{NiAl}$ nanoparticles strongly interacted with the biopolymer chains. For both strategies, the bionanocomposite aerogels contained $\sim 80 \%$ by mass of $\mathrm{LDH}$, which demonstrated the efficiency of the coprecipitation process carried out by successive impregnations. Interestingly, we showed these confined approaches can be extended to the preparation of thin bionanocomposite films which were evaluated as modified electrodes. Our results indicated that a better diffusion was achieved for the NiAl nanoparticles formed into the hydrogel compared for instance to the $\mathrm{NiAl}$

\section{REFERENCES}

Agulhon, P., Robitzer, M., David, L., and Quignard, F. (2012). Structural regime identification in ionotropic alginate gels: influence of the cation nature phases intercalated by anionic alginate. Moreover, the synthetic conditions used enhanced the accessibility of the $\mathrm{Ni}$ sites within the LDH layers. These template-assisted strategies can be considered as a simple, low cost and environmentally-friendly route to prepare $\mathrm{LDH}$ which can be extended to other hydrogels and $\mathrm{LDH}$ chemical compositions opening the way to new $\mathrm{LDH}$ based bionanocomposite materials.

\section{DATA AVAILABILITY STATEMENT}

The raw data supporting the conclusions of this article will be made available by the authors, without undue reservation.

\section{AUTHOR CONTRIBUTIONS}

VP and CM (CNRS senior researchers) were in charge of designing the experiments, writing, and revising the manuscript. ST (Ph.D. student) performed the experiments and the electrochemical measurements. All authors contributed to the article and approved the submitted version.

\section{FUNDING}

ST thanks the Algerian Ministry of Higher Education and Scientific Research for the Ph.D. grant and for supporting the mobility.

\section{SUPPLEMENTARY MATERIAL}

The Supplementary Material for this article can be found online at: https://www.frontiersin.org/articles/10.3389/fchem. 2020.561975/full\#supplementary-material

and alginate structure. Biomacromolecules 13, 215-220. doi: 10.1021/bm2 $01477 \mathrm{~g}$

Agulhon, P., Robitzer, M., Habas, J. P., and Quignard, F. (2014). Influence of both cation and alginate nature on the rheological behavior 
of transition metal alginate gels. Carbohydr. Polym. 112, 525-531. doi: 10.1016/j.carbpol.2014.05.097

Alcantara, A. C. S., Aranda, P., Darder, M., and Ruiz-Hitzky, E. (2010). Bionanocomposites based on alginate-zein/layered double hydroxide materials as drug delivery systems. J. Mater. Chem. 20, 9495-9504. doi: 10.1039/c0jm01211d

Anantharaj, S., Karthick, K., and Kundu, S. (2017). Evolution of layered double hydroxides (LDH) as high performance water oxidation electrocatalysts: a review with insights on structure, activity and mechanism. Mater. Today Energy 6, 1-26. doi: 10.1016/j.mtener.2017.07.016

Brayner, R., Vaulay, M. J., Fiévet, F., and Coradin, T. (2007). Alginate-mediated growth of $\mathrm{Co}, \mathrm{Ni}$, and $\mathrm{CoNi}$ nanoparticles: influence of the biopolymer structure. Chem. Mater. 19, 1190-1198. doi: 10.1021/cm062580q

Cai, Z., Bu, X., Wang, P., Ho, J. C., Yang, J., and Wang, X. (2019). Recent advances in layered double hydroxide electrocatalysts for the oxygen evolution reaction. J. Mater. Chem. A 7, 5069-5089. doi: 10.1039/C8TA11273H

Chatterjee, A., Bharadiya, P., and Hansora, D. (2019). Layered double hydroxide based bionanocomposites. Appl. Clay Sci. 177, 19-36. doi: $10.1016 /$ j.clay.2019.04.022

Choi, G., Eom, S., Vinu, A., and Choy, J. H. (2018a). 2D nanostructured metal hydroxides with gene delivery and theranostic functions; a comprehensive review. Chem. Rec. 18, 1033-1053. doi: 10.1002/tcr.201700091

Choi, G., Kim, T. H., Oh, J. M., and Choy, J. H. (2018b). Emerging nanomaterials with advanced drug delivery functions; focused on methotrexate delivery. Coord. Chem. Rev. 359, 32-51. doi: 10.1016/j.ccr.2018.01.007

Chtchigrovsky, M., Lin, Y., Ouchaou, K., Chaumontet, M., Robitzer, M., Quignard, F., et al. (2012). Dramatic effect of the gelling cation on the catalytic performances of alginate-supported palladium nanoparticles for the suzukimiyaura reaction. Chem. Mater. 24, 1505-1510. doi: 10.1021/cm3003595

Darder, M., Lopez-Blanco, M., Aranda, P., Leroux, F., and Ruiz-Hitzky, E. (2005). Bio-nanocomposites based on layered double hydroxides. Chem. Mater. 17, 1969-1977. doi: 10.1021/cm0483240

dos Santos Araújo, P., Belini, G. B., Mambrini, G. P., Yamaji, F. M., and Waldman, W. R. (2019). Thermal degradation of calcium and sodium alginate: a greener synthesis towards calcium oxide micro/nanoparticles. Int. J. Biol. Macromol. 140, 749-760. doi: 10.1016/j.ijbiomac.2019.08.103

Fan, G., Li, F., Evans, D. G., and Duan, X. (2014). Catalytic applications of layered double hydroxides: recent advances and perspectives. Chem. Soc. Rev. 43, 7040-7066. doi: 10.1039/C4CS00160E

Faour, A., Mousty, C., Prevot, V., Devouard, B., De Roy, A., Bordet, P., et al. (2012). Correlation among structure, microstructure, and electrochemical properties of NiAl- $-\mathrm{CO}_{3}$ layered double hydroxide thin films. J. Phys. Chem. C 116, 15646-15659. doi: 10.1021/jp300780w

Forano, C., Costantino, U., Prévot, V., and Gueho, C. T. (2013). "Chapter 14.1 - Layered double hydroxides (LDH)," in Developments in Clay Science. eds F. Bergaya and G. Lagaly (Oxford: Elsevier), 745-782.

Gao, C., Yu, X. Y., Luo, T., Jia, Y., Sun, B., Liu, J. H., et al. (2014). Millimeter-sized $\mathrm{Mg}-\mathrm{Al}-\mathrm{LDH}$ nanoflake impregnated magnetic alginate beads (LDH-n-MABs): a novel bio-based sorbent for the removal of fluoride in water. J. Mater. Chem. A 2, 2119-2128. doi: 10.1039/C3TA13526H

Géraud, E., Rafqah, S., Sarakha, M., Forano, C., Prevot, V., and Leroux, F. (2008). Three dimensionally ordered macroporous layered double hydroxides: preparation by templated impregnation/coprecipitation and pattern stability upon calcination. Chem. Mater. 20, 1116-1125. doi: 10.1021/cm70 $2755 \mathrm{~h}$

Gu, P., Zhang, S., Li, X., Wang, X., Wen, T., Jehan, R., et al. (2018). Recent advances in layered double hydroxide-based nanomaterials for the removal of radionuclides from aqueous solution. Environ. Pollut. 240, 493-505. doi: 10.1016/j.envpol.2018.04.136

Jaouen, V., Brayner, R., Lantiat, D., Steunou, N., and Coradin, T. (2010). In situ growth of gold colloids within alginate films. Nanotechnology 21:18. doi: 10.1088/0957-4484/21/18/185605

Jin, W., and Park, D. H. (2019). Functional layered double hydroxide nanohybrids for biomedical imaging. Nanomaterials 9:1404. doi: 10.3390/nano91 01404

Kim, P. N. T. (2014). Layered double hydroxide-alginate/polyvinyl alcohol beads: fabrication and phosphate removal from aqueous solution. Environ. Technol. 35, 2829-2836. doi: 10.1080/09593330.2014.924564
Kimling, M. C., and Caruso, R. A. (2012). Sol-gel synthesis of hierarchically porous $\mathrm{TiO}_{2}$ beads using calcium alginate beads as sacrificial templates. J. Mater. Chem. 22, 4073-4082. doi: 10.1039/c2jm15720a

Lee, C. G., and Kim, S. B. (2013). Magnetic alginate-layered double hydroxide composites for phosphate removal. Environ. Technol. 34, 2749-2756. doi: 10.1080/09593330.2013.788043

Leroux, F., Gachon, J., and Besse, J. P. (2004). Biopolymer immobilization during the crystalline growth of layered double hydroxide. J. Solid State Chem. 177, 245-250. doi: 10.1016/j.jssc.2003.08.013

Liang, B. L., Wang, J. F., Shu, Y. Q., Yin, P. G., and Guo, L. (2017). A biomimetic ion-crosslinked layered double hydroxide/alginate hybrid film. RSC Adv. 7, 32601-32606. doi: 10.1039/C7RA04577H

Liu, J. C., Qi, B., and Song, Y. F. (2020). Engineering polyoxometalateintercalated layered double hydroxides for catalytic applications. Dalton Trans. 49, 3934-3941. doi: 10.1039/C9DT03911B

Liu, L., Wang, W., and Hu, Y. (2015). Layered double hydroxide-decorated flexible polyurethane foam: significantly improved toxic effluent elimination. RSC Adv. 5, 97458-97466. doi: 10.1039/C5RA19414H

Mahdi, R., Guerard-Helaine, C., Laroche, C., Michaud, P., Prevot, V., Forano, C., et al. (2015). Polysaccharide-layered double hydroxide-aldolase biohybrid beads for biocatalysed CC bond formation. J. Mol. Catal. B Enzym. 122, 204-211. doi: 10.1016/j.molcatb.2015.07.014

Mahkam, M., Davatgar, M., Rezvani, Z., and Nejati, K. (2013). Preparation of $\mathrm{pH}$-sensitive polymers/layered double hydroxide hybrid beads for controlled release of insulin. Int. J. Polym. Mater. Polym. Biomater. 62, 57-60. doi: 10.1080/00914037.2011.617337

Martin, J., Jack, M., Hakimian, A., Vaillancourt, N., and Villemure, G. (2016). Electrodeposition of $\mathrm{Ni}$-Al layered double hydroxide thin films having an inversed opal structure: application as electrochromic coatings. J. Electroanal. Chem. 780, 217-224. doi: 10.1016/j.jelechem.2016.09.022

Mondal, D., and Villemure, G. (2012). Improved reversibility of color changes in electrochromic $\mathrm{Ni}-\mathrm{Al}$ layered double hydroxide films in presence of electroactive anions. J. Electroanal. Chem. 687, 58-63. doi: 10.1016/j.jelechem.2012.09.046

Mousty, C., and Prévot, V. (2013). Hybrid and biohybrid layered double hydroxides for electrochemical analysis. Anal. Bioanal. Chem. 405, 3513-3523. doi: 10.1007/s00216-013-6797-1

Mousty, C., and Walcarius, A. (2015). Electrochemically assisted deposition by local $\mathrm{pH}$ tuning: a versatile tool to generate ordered mesoporous silica thin films and layered double hydroxide materials. J. Solid State Electrochem. 19, 1905-1931. doi: 10.1007/s10008-014-2570-4

Pan, H., Wang, W., Shen, Q., Pan, Y., Song, L., Hu, Y., et al. (2016). Fabrication of flame retardant coating on cotton fabric by alternate assembly of exfoliated layered double hydroxides and alginate. RSC Adv. 6, 111950-111958. doi: 10.1039/C6RA21804K

Patel, R., Park, J. T., Patel, M., Dash, J. K., Gowd, E. B., Karpoormath, R., et al. (2018). Transition-metal-based layered double hydroxides tailored for energy conversion and storage. J. Mater. Chem. A 6, 12-29. doi: 10.1039/C7TA09370E

Prevot, V., and Tokudome, Y. (2017). 3D hierarchical and porous layered double hydroxide structures: an overview of synthesis methods and applications. $J$. Mater. Sci. 52, 11229-11250. doi: 10.1007/s10853-017-1067-9

Primo, A., Marino, T., Corma, A., Molinari, R., and García, H. (2011). Efficient visible-light photocatalytic water splitting by minute amounts of gold supported on nanoparticulate $\mathrm{CeO} 2$ obtained by a biopolymer templating method. JACS. 133, 6930-6933. doi: 10.1021/ja2011498

Rezvani, Z., and Shahbaei, M. (2015). Bionanocomposites based on alginate and chitosan/layered double hydroxide with ciprofloxacin drug: investigation of structure and controlled release properties. Polym. Compos. 36, 1819-1825. doi: 10.1002/pc.23089

Sanchez-Paniagua Lopez, M., Leroux, F., and Mousty, C. (2010). Amperometric biosensors based on LDH-alginate hybrid nanocomposite for aqueous and non-aqueous phenolic compounds detection. Sens. Actuat. B 150, 36-42. doi: 10.1016/j.snb.2010.07.045

Scavetta, E., Mignani, A., Prandstraller, D., and Tonelli, D., (2007). Electrosynthesis of thin films of $\mathrm{Ni}$, Al hydrotalcite like compounds. Chem. Mater 19, 4523-4529. doi: $10.1021 / \mathrm{cm} 071132 \mathrm{v}$

Sun, J., Chen, Y., Yu, H., Yan, L., Du, B., and Pei, Z. (2018). Removal of $\mathrm{Cu}^{2+}, \mathrm{Cd}^{2+}$ and $\mathrm{Pb}^{2+}$ from aqueous solutions by magnetic alginate microsphere based on 
Fe3O4/MgAl-layered double hydroxide. J. Colloid Interface Sci. 532, 474-484. doi: 10.1016/j.jcis.2018.07.132

Taviot-Guého, C., Prévot, V., Forano, C., Renaudin, G., Mousty, C., and Leroux, F. (2018). Tailoring hybrid layered double hydroxides for the development of innovative applications. Adv. Funct. Mater. 28:1703868. doi: 10.1002/adfm.201703868

Taviot-Gueho, C., Vialat, P., Leroux, F., Razzaghi, F., Perrot, H., Sel, O., et al. (2016). Dynamic characterization of inter- and intralamellar domains of cobaltbased layered double hydroxides upon electrochemical oxidation. Chem. Mater. 28, 7793-7806. doi: 10.1021/acs.chemmater.6b03061

Tichit, D., Layrac, G., and Gérardin, C. (2019). Synthesis of layered double hydroxides through continuous flow processes: a review. Chem. Eng. J. 369, 302-332. doi: 10.1016/j.cej.2019.03.057

Tokarev, A., Agulhon, P., Long, J., Quignard, F., Robitzer, M., Ferreira, R. A. S., et al. (2012). Synthesis and study of Prussian blue type nanoparticles in an alginate matrix. J. Mater. Chem. 22, 20232-20242. doi: 10.1039/c2jm33585a

Tokudome, Y., Morimoto, T., Tarutani, N., Vaz, P. D., Nunes, C. D., Prevot, V., et al. (2016). Layered double hydroxide nanoclusters: aqueous concentrated stable and catalytically active colloids toward green chemistry. ACS Nano 10, 5550-5559. doi: 10.1021/acsnano.6b02110

Tonelli, D., Scavetta, E., and Giorgetti, M. (2013). Layered-double-hydroxidemodified electrodes: electroanalytical applications. Anal. Bioanal. Chem. 405, 603-614. doi: 10.1007/s00216-012-6586-2

Vialat, P., Leroux, F., and Mousty, C. (2015). Electrochemical properties of layered double hydroxides containing 3d metal cations. J. Solid State Electrochem. 19, 1975-1983. doi: 10.1007/s10008-014-2671-0

Vialat, P., Leroux, F., Taviot-Gueho, C., Villemure, G., and Mousty, C. (2013). Insights into the electrochemistry of $\left(\mathrm{CoxNi}_{(1--x)}\right) 2 \mathrm{Al}-$ NO3 layered double hydroxides. Electrochim. Acta 107, 599-610. doi: 10.1016/j.electacta.2013.06.033

Wang, Z., Kale, G. M., Yuan, Q., and Ghadiri, M. (2012). X-Ray microtomography of freeze dried nickel alginate beads and transformation into $\mathrm{NiO}$ nanopowders. RSC Adv. 2, 9993-9997. doi: 10.1039/c2ra21171h

Xie, W., Song, Y., Li, S., Shao, M., and Wei, M. (2019). Integrated nanostructural electrodes based on layered double hydroxides. Energy Environ. Mater. 2, 158-171. doi: 10.1002/eem2.12033

Xu, M., Wei, M. (2018). Layered double hydroxide-based catalysts: recent advances in preparation structure and applications. Adv.Funct. Maters 28:1802943. doi: 10.1002/adfm.201802943
Yang, J. S., Xie, Y. J., and He, W. (2011). Research progress on chemical modification of alginate: a review. Carbohydr. Polym. 84, 33-39. doi: 10.1016/j.carbpol.2010.11.048

Yang, X., Kim, E., Liu, Y., Shi, X. W., Rubloff, G. W., Ghodssi, R., et al. (2010). In-film bioprocessing and immunoanalysis with electroaddressable stimuli-responsive polysaccharides. Adv. Funct. Mater. 20, 1645-1652. doi: 10.1002/adfm.200902092

Yang, Z., Wei, J., Zeng, G., Zhang, H., Tan, X., Ma, C., et al. (2019). review on strategies to $\mathrm{LDH}$-based materials to improve adsorption capacity and photoreduction efficiency for $\mathrm{CO}_{2}$. Coord. Chem. Rev. 386, 154-182. doi: 10.1016/j.ccr.2019.01.018

Yu, X., Wen, T., Cao, P., Shan, L., and Li, L. (2019). Alginate-chitosan coated layered double hydroxide nanocomposites for enhanced oral vaccine delivery. J. Colloid Interface Sci. 556, 258-265. doi: 10.1016/j.jcis.2019. 08.027

Zhang, G., Zhang, X., Meng, Y., Pan, G., Ni, Z., and Xia, S. (2020). Layered double hydroxides-based photocatalysts and visible-light driven photodegradation of organic pollutants: a review. Chem. Eng. J. 392:123684. doi: 10.1016/j.cej.2019.123684

Zhang, J. P., Wang, Q., Xie, X. L., Li, X., and Wang, A. Q. (2010). Preparation and swelling properties of $\mathrm{pH}$-sensitive sodium alginate/layered double hydroxides hybrid beads for controlled release of diclofenac sodium. J. Biomed. Mater. Res. B Appl. Biomater. 92, 205-214. doi: 10.1002/jbm.b.31507

Zhang, R., Ai, Y., and Lu, Z. (2020). Application of multifunctional layered double hydroxides for removing environmental pollutants: recent experimental and theoretical progress. J. Environ. Chem. Eng. 8:103908. doi: $10.1016 /$ j.jece.2020.103908

Conflict of Interest: The authors declare that the research was conducted in the absence of any commercial or financial relationships that could be construed as a potential conflict of interest.

Copyright (c) 2020 Prevot, Touati and Mousty. This is an open-access article distributed under the terms of the Creative Commons Attribution License (CC BY). The use, distribution or reproduction in other forums is permitted, provided the original author(s) and the copyright owner(s) are credited and that the original publication in this journal is cited, in accordance with accepted academic practice. No use, distribution or reproduction is permitted which does not comply with these terms. 